ISSN (online) - 2520-6311; ISSN (print) - 2520-6761

\title{
Factors Affecting Customer Satisfaction of the Ride-sharing Industry in Bangladesh
}

http://doi.org/10.21272/bel.3(4).74-80.2019

Mohsina Jahan, ORCID: https://orcid.org/0000-0002-0215-7517

BBA in Marketing, Faculty of Business Studies, University of Dhaka, Bangladesh

\begin{abstract}
This paper summarizes the arguments and counterarguments within the statistical analysis on the issue of customer satisfaction with the ride-sharing industry in Bangladesh. The objective of this study is to explore and assess the factors that affect the satisfaction level of ride-sharing users in Bangladesh. Systematization of literary sources and approaches for solving the problem of customer dissatisfaction indicates that there are real problems with the services of the ride-sharing companies. The relevance of the decision of this statistical analysis is that speed, cost, and convenience of ride influence the level of customer satisfaction. As the ridesharing companies store the personal data while using the application, they were accused of using those data illegally and without users' consent which goes against the business ethics principles. Investigation of the topic proves that if the ride-sharing companies can reduce the cost of the ride, increase the speed and convenience of the ride and run their business ethically customers will be more satisfied than before. Analysis in the paper is carried out in the following logical sequence: the statistical data available are analyzed, and then a survey is done, which reveals some factors that affect customer satisfaction. Methodological tools of the research methods were analysis and synthesis of the available data, survey, and statistical methods: hypothesis testing through binary logistic regression analysis with Hosmer-Lemeshow test which proves that there are significant relationships between some factors. The object of the research is factors that affect the customer satisfaction of the ride-sharing industry in Bangladesh. The study found speed of ride as the most significantly influential factor (regression coefficient) ([Coef.] $=2.707$, Odds Ratio $[\mathrm{OR}]=14.9899, \mathrm{p}<0.01)$ followed by cost of ride $($ Coef. $=2.291$, OR=9.8883, $\mathrm{p}<0.01)$ and convenience of ride $($ Coef. $=1.969, \mathrm{OR}=7.1641, \mathrm{p}<0.01)$. However, the security of ride, waiting time for the car and behavior of drivers were found insignificant. The model explains $78.44 \%$ deviance (Coefficient of determination, $\mathrm{R}^{2}$ $=0.7844)$ in the response variable with its constructs. And the "Hosmer-Lemeshow" goodness-of-fit score (1.00) is also above the standard threshold (0.05), which indicates the data fit well with the model. The research empirically confirms and statistically proves that reducing the cost, increasing the speed and convenience of the ride can significantly impact customer satisfaction along with some other factors including maintaining business ethics, the confidentiality of personal data, improving vehicle fitness, service availability, and safety driving. The findings of this study are expected to be helpful for ride-sharing service providers to gain a better understanding of the factors that impact the customer satisfaction of the ridesharing industry in Bangladesh.
\end{abstract}

Keywords: Bangladesh, Business ethics, Congestion, Customer satisfaction, Ride-sharing.

JEL Classification: D11, D12, M1.

Cite as: Jahan, M. (2019). Factors Affecting Customer Satisfaction of the Ride-sharing Industry in Bangladesh. Business Ethics and Leadership, 3(4), 74-80. http://doi.org/10.21272/bel.3(4).74-80.2019.

(C) The Author, 2019. This article is published with open access at Sumy State University.

\section{Introduction}

Ride-sharing is referred to two or more people traveling to a particular route or destination by using the same car. According to Transport for London (2007), users can choose to use the service for a part of the journey or the entire trip itself. Individuals got permission to access a car that is owned by an individual or an institution in exchange for some sort of monetary payment (Le Vine et al., 2014). Ride-sharing is operated through an application. This application is free and can be downloaded from Apple Store or Google Play and sign up required using a cell phone number and e-mail. They would then be able to tap the screen to hail a taxi and a driver will use GPS to discover their location in minutes. As the application stores some personal data while using the service, companies are accused of using those data illegally for business purposes without the consent of the customers, there arises some question regarding the business ethics of the ride- 
sharing companies. Dhaka city is a center of congestion and the 7th most populous city in the world with nearly 39 million residents (Malone, 2006). Since Dhaka has a population of almost 17 million people and an area of 1.528 square kilometers (Asian Development Bank, 2011), the need for transportation will always be at a higher cost than expected. According to Bangladesh Road Transport Authority (2015), it was estimated that there were 1115,654 registered vehicles in Dhaka city alone and in the whole country 3419,884, which was a figure assessed till April 2018, the actual figure might just be higher. Different modes of transportation are used by commuters to meet regular traveling needs including buses, CNGs, rickshaws, and cars amongst other means of transport. With the increase in income, the number of private cars on the roads is also increasing, creating more traffic congestion. But the condition of general people who do not have any private cars is becoming miserable. It is really hard to get into public transportation especially for women. But recently ride-sharing is bringing great relief to the inhabitants of the people of Dhaka city and some other districts. Bangladesh witnessed the leap of ride-sharing space with the emergence of Pathao, the most popular local ride-sharing company which started the journey in 2016 and the entrance of Uber in the Bangladesh market in late 2016. Besides Pathao and Uber, quite a few ride-sharing companies are emerging to cater to the increasing public demand. As of November 2017, an estimated 500,000 commuters have opted to avail ride-sharing on cars and bikes via apps - also known as e-hailing (IDLC finance ltd, 2018). From the perspective of Bangladesh, there is a great shortage of transportation to the number of the total population. The quality of transportation is not good. This is the main reason that people have been widely accepted the concept of ride-sharing but the actual satisfaction level and the factors affecting the satisfaction level of the ride-sharing consumers have not been measured yet. To the best of my knowledge, not enough studies have been done regarding assessing the factors affecting the satisfaction level of the ride-sharing users in Bangladesh. So, the objective of this study is to assess the factors that affect the customer satisfaction of the ride-sharing industry in Bangladesh. This study is expected to close the gap of the existing literature by providing the research results which will be helpful for the ride-sharing companies improving their service and prepare well for meeting the future needs of the customers.

About ride sharing: Ride-sharing services may be offered in two basic forms: static and dynamic ride sharing.

1) Static Ride Sharing: In static ride-sharing, clients can demand to offer or request a ride. Fruitful matches between clients happen when clients locate each other based on the request which was distributed. The application assembles a great deal of information, helping clients to limit their search based on their preferences. Nonetheless, it must be noticed that it doesn't work continuously and clients can just communicate through emails which can cause noise in exchange for information.

2) Dynamic Ride Sharing: Dynamic ride-sharing is vigorously dependent on innovation and cell phones. It permits clients access to the application continuously and the GPS tracker helps pinpoint the exact location of the fleet of the vehicle. Based on the input of the users, the app finds the overlapping routes. The application can be operated by the users either as a passenger or as a driver. The driver is the one in charge of choosing which routes are to be taken. He will enter the starting point and destination, time of take-off, vehicle model, color and license plate of the vehicle. The driver will, at last, acknowledge or reject the solicitation of travelers to get to the vehicle. The traveler gives pertinent information which includes his or her current area, destination area and desired departure time. The traveler will demand the driver for a ride. The traveler at that point meets the driver at a predetermined meeting point and time after the driver acknowledges his or her ride request (Haddad et al., 2013).

\section{Literature Review}

The satisfaction of the ride-sharing users and the sustainability of the ride-sharing industry depends on the positive influence of multi-furious factors. In this regard, the findings of the prominent research studies have been reviewed in the following section. Hamari et al. (2016) examined that increased concern about the environmental change in the mix with specialized accomplishments is two principle contributors why sharing economy, the peer-to-peer-based action of acquiring giving or sharing the entrance to products and ventures facilitated through network-based online administrations turned into an attractive alternative for consumers. Numerous studies have revealed that ride-sharing has many advantages for the client as well as for urban areas districts and organizations (Chan and Shaheen, 2012). Other than lessening $\mathrm{CO}_{2}$ emission and fuel utilization (Jacobson and King, 2009), it additionally spares the users' money and time (Teubner and Flath, 2015).

Research from Stiglic et al. (2016) exhibits the effect of client adaptability on the execution of a ride-sharing framework. The computational examination demonstrates that participants' adaptability as far as for taking 
ISSN (online) - 2520-6311; ISSN (print) - 2520-6761

off and entry times, just as drivers' willingness to drive a detour, assume key jobs in facilitating the matching process. Shmueli et al. (2015) consider the potential advantage of ride-sharing by analyzing a dataset of more than 14 million taxi trips in New York. As indicated by Shmueli et al. (2015) over 70\% of the taxi rides can be shared if the travelers can wait for 30 minutes or more (in the same place.). The exploration referenced above has demonstrated that ride-sharing does not just prompt environmental, social and financial advantages, it has additionally theoretically high potential and flexibility. Remembering this, the question arises why ride-sharing is still not a widely accepted mean of transportation. Gargiulo et al. (2015) studied that one possible solution to increase clients' trust and satisfy their desire to make a user-centered service design approach. Such a user-centered service design plan of an exploratory dynamic ride-sharing system was the primary objective of the above-mentioned study. Their service, a mobile application called Virtual Bus which enables clients to get arrangements in real life for sharing car rides, was structured, prototyped and tested including clients in every step to guarantee ease of use from the very first moment. An online survey among 500 members featured that trust has a critical significance, among clients as well as concerning information gathering through the portable application. Respondents wished to have the capacity to offer reviews to different clients (86\%), find trust in the driver $(80 \%)$ and make certain to get the correct repayment before the coordinating happens (84\%). Rokonuzzaman (2018) stated that regulatory barriers, increased competition, weak technology will force companies to increase the quality of service and reduce costs which will lead to a growing loss for the company. The ridesharing business may have to prepare to face bankruptcy if self-driving cars take too long to show up. Hasan and Birgach (2016) examined that there are different factors behind this reason, for example, another rising class of customers with a distinct fascination for sharing; value awareness; a growing perception of the eco-productivity of the sharing economy; and a rising business-to-business (B2B) sector that contributes to operating at the highest capacity. Some other factors including advances in software engineering and information technology, especially in social media and digital platforms, have made a remarkable situation for the development and increasing speed of the sharing economy. Saadat et al. (2018) examined that users have a positive perception regarding the service of ride-sharing companies. Customers are not willing to wait a long time to get into the car. They want the cost to be low and the services to be convenient. A large number of participants expressed that security concerns would act as an obstacle to the sustainability of ride-sharing services. As per the findings from (Gargiulo et al., 2015; Ghoseiri et al., 2011; Cici et al., 2013) security concerns were characterized as one of the principal boundaries to dynamic ridesharing by a few different specialists.

\section{Methodology and Research Methods}

According to the type of research problem, a descriptive research design is more appropriate here. So, the quantitative research technique has been used. To test the research hypothesis, data were collected through an online survey questionnaire. Secondary data was collected from company websites, journals, newspapers, and published research works. A convenient non-probability random sampling technique has been used for this study. Respondents participated in this survey were from many districts including Dhaka, Narayanganj, Narshingdi, and Gazipur. People from various professions participated in the survey. A structured questionnaire was developed in English. The questionnaire was anonymous and did not hamper the privacy of the respondents. The consent of the respondents was taken to use this on research purposes. The survey questionnaire mostly covered the demographic information, six independent variables and last of all, the dependent variable. The independent variables in the questionnaire were created in a one to five-point "Likert Scale". Since the dependent variable in this study is "customer satisfaction" and the response is categorized in either "Yes" or "No", it was a binary classification problem. Several studies (Cook, 1998; Davis and Offord, 1997; Hair et al., 1998) suggested that binary logistic regression fits better in this circumstance. Therefore, the binary logistic regression model is used here to test the research hypothesis. Statistical software "Minitab" is used to analyze the data. The sample size is 158 . The sampling frame includes people from all professions and age groups. The general population size of this industry is unknown because not enough studies have been done measuring the population size of the ride-sharing industry. Thus, 550 respondents were approached based on convenience, among whom 24 were found unaware of ridesharing and were thus eliminated. Among the rest, 526 respondents who were aware of ride-sharing, 368 found non-users and thus eliminated. Therefore, a total of 158 respondents were the final sample size for this research. To achieve the research objective, six independent variables were selected including speed of the ride, cost of the ride, the security of ride, convenience of the ride, waiting time for the car, and drivers' behavior based on existing literature relating to customer satisfaction of the ride-sharing companies. Several studies (Cici et al., 2013; Gargiulo et al., 2015; Ghoseiri et al., 2011; Rokonuzzaman, 2018; Saadat et al., 2018; Shmueli et al., 2015; Stiglic et al., 2016; Teubner and Flath, 2015) show that the above-mentioned 
factors were considered by users when choosing a ride from any company. These considerations impact the level of satisfaction which in turn will predict the ability of this industry to sustain in the future. However, six independent variables were considered to measure their impacts on customer satisfaction, which is shown as the research framework in Figure 1.

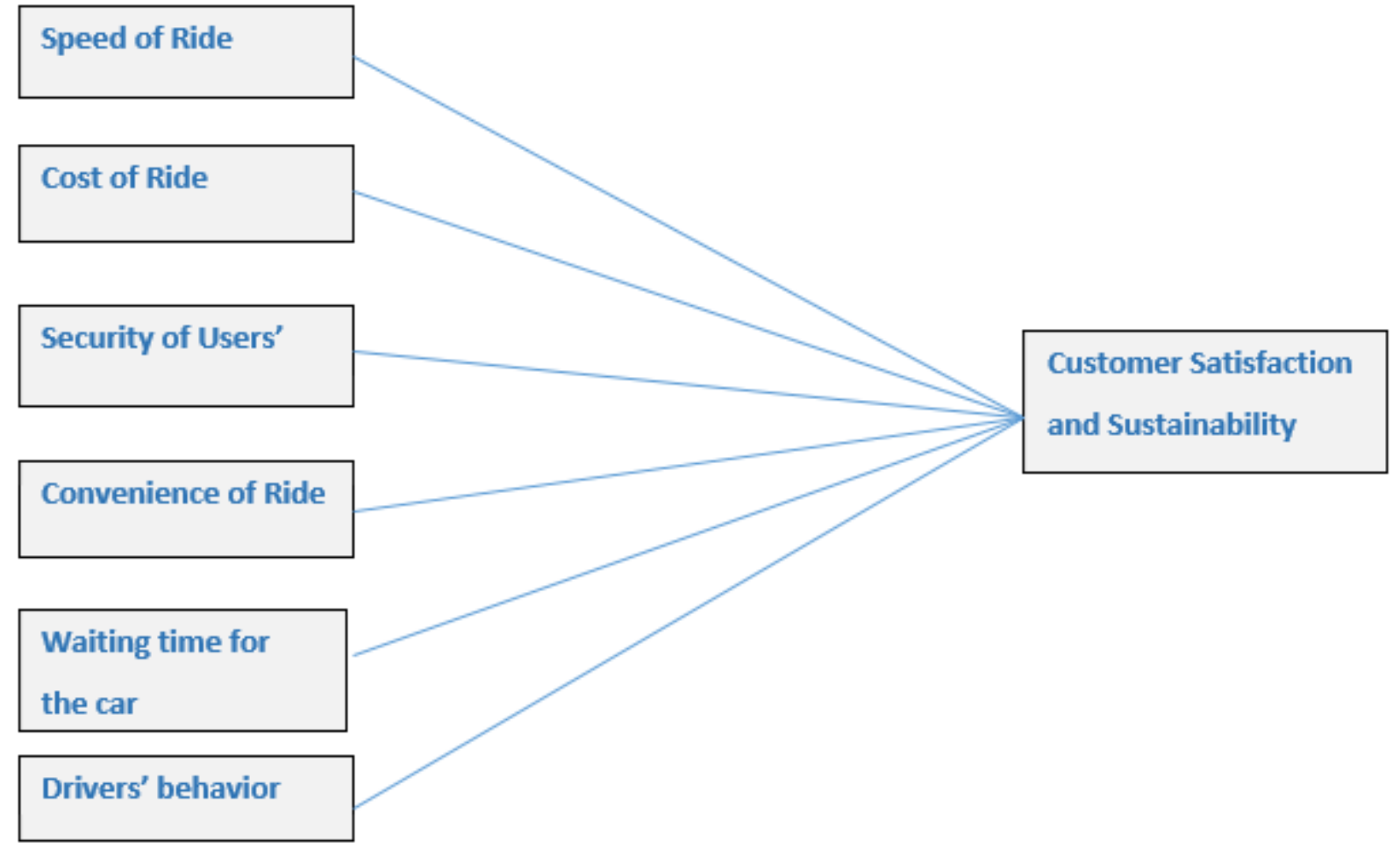

Figure 1. A research framework

Source: Own elaboration of the author

From the mentioned framework, keeping the research objective in mind, the following six research hypotheses have been developed to be tested.

H1: Speed of ride has a positive impact on customer satisfaction.

$\mathrm{H} 2$ : Cost of ride affects customer satisfaction.

H3: Users' security significantly impacts customer satisfaction.

$\mathrm{H} 4$ : Convenience of the ride has a positive impact on customer satisfaction.

H5: Waiting time for the car significantly impacts customer satisfaction.

H6: Drivers' behavior affects the level of satisfaction.

\section{Results}

Respondents' demographic characteristics are given in Table 1.

Table 1. Respondents' demographic information

\begin{tabular}{|l|c|c|}
\hline & \multicolumn{1}{|c|}{ Frequency } & Percentage \\
\hline Gender & \multicolumn{2}{|c|}{$60 \%$} \\
\hline Male & 95 & $40 \%$ \\
\hline Female & 63 & $3.8 \%$ \\
\hline Age & 6 & $95.6 \%$ \\
\hline Under 20 & 151 & $0.6 \%$ \\
\hline $\mathbf{2 1 - 3 0}$ & 1 & $94.4 \%$ \\
\hline $\mathbf{3 1 - 4 0}$ & & $5 \%$ \\
\hline Profession & 150 & $0.6 \%$ \\
\hline Student & 7 & \\
\hline Service Holder & 1 & \\
\hline Others profession & & \\
\hline
\end{tabular}

Source: Own elaboration of the author 
ISSN (online) - 2520-6311; ISSN (print) - 2520-6761

Among the total respondents, $60 \%$ were males. As the non-probability random sampling technique was used for this research it proves that males are more likely to use ride-sharing services than females. Among all of the profession student represented $94.4 \%$ of the total sample. It is clear that students constitute the major market for ride-sharing services. So, the ride-sharing service providers should target their marketing activities mostly towards students. From the table, we can see that (21-30) age bracket represents $95.6 \%$ of the total sample chosen which means young generations represent the attractive market for ride-sharing services.

Table 2 shows the descriptive statistics of six independent variables that are, speed, cost, security, convenience, waiting for time and drivers' behavior.

Table 2. Factors affecting customer satisfaction

\begin{tabular}{|c|c|c|c|c|c|c|}
\hline & & Very high & High & No opinion & Low & Very low \\
\hline \multirow[t]{2}{*}{ Speed of ride } & Frequency & 19 & 16 & 87 & 31 & 5 \\
\hline & Percentage & $12 \%$ & $10 \%$ & $55 \%$ & $20 \%$ & $3 \%$ \\
\hline \multirow[t]{2}{*}{ Cost of ride } & Frequency & 8 & 24 & 74 & 30 & 8 \\
\hline & Percentage & $5 \%$ & $17 \%$ & $51 \%$ & $21 \%$ & $6 \%$ \\
\hline \multirow[t]{2}{*}{ Security of ride } & Frequency & 9 & 27 & 85 & 27 & 10 \\
\hline & Percentage & $6 \%$ & $17 \%$ & $54 \%$ & $17 \%$ & $6 \%$ \\
\hline \multirow[t]{2}{*}{ Convenience of ride } & Frequency & 15 & 52 & 66 & 20 & 5 \\
\hline & Percentage & $9 \%$ & $33 \%$ & $42 \%$ & $13 \%$ & $3 \%$ \\
\hline \multirow[t]{2}{*}{ Waiting time for car } & Frequency & 8 & 24 & 60 & 41 & 25 \\
\hline & Percentage & $5 \%$ & $15 \%$ & $38 \%$ & $26 \%$ & $16 \%$ \\
\hline \multirow[t]{2}{*}{ Drivers' behavior } & Frequency & 8 & 22 & 92 & 18 & 18 \\
\hline & Percentage & $5 \%$ & $14 \%$ & $58 \%$ & $12 \%$ & $11 \%$ \\
\hline \multirow{3}{*}{$\begin{array}{l}\text { Customer } \\
\text { satisfaction }\end{array}$} & & \multicolumn{3}{|c|}{ Yes } & \multicolumn{2}{|c|}{ No } \\
\hline & Frequency & \multirow{2}{*}{\multicolumn{3}{|c|}{120}} & \multicolumn{2}{|c|}{38} \\
\hline & Percentage & & & & \multicolumn{2}{|c|}{$24.1 \%$} \\
\hline
\end{tabular}

Source: Own elaboration of the author

The table also shows the distribution of the dependent variable, that is, customer satisfaction, $75.9 \%$ were found satisfied with the services of ride-sharing companies, whereas $24.1 \%$ were found dissatisfied. Respondents provided opinions regarding the improvement of the service that will increase customer satisfaction including decreasing cost of the ride, increasing the security of personal data, maintaining business ethics principles, improving vehicle fitness, improving drivers' skills regarding safe driving, use of GPS, and making services more available.

\section{Results of hypotheses testing}

Data analysis has been done using statistical software Minitab. The logistic regression model is used to test the hypotheses. A significant level of 0.05 is considered for this model. Decisions regarding hypotheses testing have been made by comparing the variables' p-value with models' significance level. The regression coefficient indicates the nature of the relationship between the independent and dependent variables, whereas the odds ratio explains the magnitude of the effect of independent variables on the dependent variable. The results of hypotheses testing are given in Table 3.

Table 3. Results of hypotheses testing through logistic regression

\begin{tabular}{|c|l|c|c|c|l|}
\hline HYPOTHESES & \multicolumn{1}{|c|}{ VARIABLE } & COEF. & OR & P & \multicolumn{1}{|c|}{ RESULT } \\
\hline 1 & Speed of ride & 2.707 & 14.9899 & 0.000 & Supported \\
\hline 2 & Cost of ride & 2.291 & 9.8883 & 0.000 & Supported \\
\hline 3 & Security of ride & 1.34 & 3.8338 & 0.351 & Not supported \\
\hline 4 & Convenience of ride & 1.969 & 7.1641 & 0.002 & Supported \\
\hline 5 & Waiting time for car & 0.240 & 1.2709 & 0.750 & Not supported \\
\hline 6 & Drivers' behavior & 1.13 & 3.1102 & 0.370 & Not supported \\
\hline
\end{tabular}

Source: Own elaboration of the author

The study found speed of ride as the most significantly influential factor (regression coefficient [Coef.] $=2.707$, Odds ratio $[\mathrm{OR}]=14.9899, \mathrm{P}<0.01)$ followed by cost of ride $($ Coef. $=2.291$, OR=9.8883, $\mathrm{P}<0.01)$ and convenience of ride (Coef. $=1.969, \mathrm{OR}=7.1641, \mathrm{P}<0.01$ ). However, the security of ride, waiting time for the car and behavior of drivers were found insignificant. If speed is increased by one layer (ex. from high to 
very high), customers will be 14.99 times more satisfied than before. If cost is reduced by one level (ex. from low to very low), satisfaction will be increased by 9.89 times. Finally, when one level of convenience will be increased, satisfaction will be increased by 7.16 times.

\section{Model summary and goodness-of-fit tests}

The model has a deviance $\mathrm{R}^{2}$ of 0.7844 , which means the model explains $78.44 \%$ of the deviance in the response variable. For binary logistic regression, the "Hosmer-Lemeshow" test is a more trustworthy indicator of how well the model fits the data (Hosmer and Lemeshow, 1980). In this model, the goodness-offit score is 1.00 that is greater than the significance level of 0.05 , which indicates that there is not enough evidence to conclude that the model does not fit the data.

\section{Conclusions and Recommendations}

Customer satisfaction is a vital issue in every service industry especially in the rides-haring industry because dissatisfaction can cause switching of customers to other service providers. The study found speed of ride as the most significantly influential factor (regression coefficient [Coef.] $=2.707$, Odds ratio [OR] $=14.9899$, $\mathrm{P}<0.01)$ followed by cost of ride (Coef. $=2.291, \mathrm{OR}=9.8883, \mathrm{P}<0.01)$ and convenience of ride $($ Coef. $=1.969$, $\mathrm{OR}=7.1641, \mathrm{P}<0.01$ ), whereas security, waiting time for the car, and behavior of drivers were found insignificant. The results of the hypothesis testing of the three insignificant variables were: security of ride [Coef.] $=1.34,[\mathrm{OR}]=3.8338, \mathrm{P}>0.01$ ), waiting time for the car $[$ Coef. $]=0.240,[\mathrm{OR}]=1.2709, \mathrm{P}>0.01$ ), and drivers' behavior [Coef.] $=1.13,[\mathrm{OR}]=3.1102, \mathrm{P}>0.01)$. According to research results, the speed, cost, and convenience of the ride can significantly impact customer satisfaction with the ride-sharing industry in Bangladesh. So, decreasing the cost, increasing the speed and convenience can improve customer satisfaction more than before. Although $76 \%$ of the total respondents were satisfied using ride-sharing, many of them mentioned that maintaining business ethics, the confidentiality of personal data, improving vehicle fitness, service availability, and safety driving can also increase customer satisfaction more than before. According to customers' opinions, it can be said that there is a very big gap between the ride-sharing companies and their customers. Customers are facing many problems and want service improvement. Ridesharing service providers should focus more attention to reduce the fare of the ride, increase the speed and convenience of the ride, and also consider the above-mentioned factors that impact customer satisfaction. The findings of this study are expected to be helpful for ride-sharing service providers to gain a better understanding of the factors that impact the level of customer satisfaction.

\section{List of abbreviations:}

$\mathrm{R}^{2}-$ Coefficient of determination;

OR - Odds Ratio;

Coef. - Regression Coefficients.

\section{References}

1. Asian Development Bank (2011). Preparing the Greater Dhaka Sustainable Urban Transport Corridor Project, Manilla.

2. Bangladesh Road Transport Authority (2015). Number of Registered Motor Vehicles in Dhaka (Year wise), Viewed at 27 March $2018 . \quad$ Available http://www.Brta.Gov.Bd/Images/Files/Statistics/Stat_Dhk_10 -15.Pdf>.

3. Chan, D. N. \& Shaheen, A. S. (2012). Ridesharing in North America: Past, Present, and Future. Transport Reviews, 32(1), 93-112. Doi: 10.1080/01441647.2011.621557.

4. Cici, B., Markopoulou, A., Frías-Martínez, E. \& Laoutaris, N. (2013). Quantifying the potential of ridesharing using call descriptive records: Proceedings of the 14th Workshop on Mobile Computing Systems and Applications, New York, USA, February 26-27, 2013. New York: Association for Computing Machinery. Doi: 10.1145/2444776.2444799.

5. Cook, R.D. (1998). Binary response variables. Regrets Graph, 5, 78-100.

6. Davis, L.J., Offord, K.P. (1997). Logistic Regression. J Pers Assess, 68, 497-507.

7. Gargiulo, E. et al. (2015). Dynamic ridesharing service: are users ready to adopt it? Procedia Manufacturing, 3, 777-784. Doi: 10.1016/j.promfg.2015.07.329 .

8. Ghoseiri, K., Haghani, A. \& Hamedi, M. (2011). Real-Time Rideshare Matching Problem, Washington, DC: The University of Maryland, Department of Civil and Environmental Engineering. Available at: http://www.mautc.psu.edu/docs/umd-2009-05.pdf. 
Business Ethics and Leadership, Volume 3, Issue 4, 2019

ISSN (online) - 2520-6311; ISSN (print) - 2520-6761

9. Haddad, Y., Cohen, Y., \& Goldsmith, R. (2013). A Dynamic Real Time Car Sharing System. Proceedings on International Conference on Soft Computing and Software Engineering, San Francisco, USA.

10.Hair, J., Anderson, R., Tatham, R., Black, W. (1998). Multivariate data analysis, $5^{\text {th }}$ ed. Upper Saddle River, NJ: Prentice Hall.

11.Hamari, J., Sjöklint, M., Ukkonen, A. (2016). Sharing Economy: Why People Participate in Collaborative Consumption. Association for information science and technology, 67(9), 2047-2059. Doi:10.1002/asi.23552.

12.Hasan, R., and Birch, M. (2016). Critical success factors behind the sustainability of the Sharing Economy. 2016 IEEE 14th International Conference on Software Engineering Research, Management and Applications (SERA), Towson, MD, pp. 287-293. Doi: 10.1109/sera.2016.7516158.

13.Hosmer, D.W., Lemeshow, S. (1980). Goodness of fit tests for the multiple logistic regression model. Common Stat Theory Methods, 9(10), 1043-1069. DOI: 10.1080/03610928008827941.

14.IDLC Finance Limited, Monthly Business Review (2018). Ride-Sharing in Bangladesh, Disrupting the Way We Commute. Available at: https://idlc.com/mbr/article.php?id=125.

15.Jacobson, S. H. \& King, D. M. (2009). Fuel saving and ridesharing in the US: Motivations, limitations, and opportunities. Transportation Research Part D, 14, 14-21. Doi: 10.1016/j.trd.2008.10.001.

16.Le Vine, S., Zolfaghari, A., \& Polak, J. (2014). Car Sharing: Evolution, Challenges, and Opportunities, Center for Transport Studies, Imperial College, London.

17.Malone, R. (2006). World's Most Congested Cities, Forbes. Available at: https://www.forbes.com/2006/12/20/worlds-most-congested-cities-biz-energycx_rm_1221congested.html\#7efa61675499. Accessed 2 September 2019.

18.Rokonuzzaman (2018). Ride Sharing Innovation Lacks Sustainability, The Financial Express. Available at: https://www.thefinancialexpress.com.bd/views/ridesharing-innovation-lacks-sustainability-1520439967. Accessed 26 March. 2019.

19.Saadat, S.Y., Ahmed, K.S., Jahan, A., Jahan, N. and Zahid, T.B. (2018). Consumers' Perceptions on Car Sharing: A Preliminary Study in Dhaka City. World Journal of Social Sciences, 8(2), 43-56. Available at: https://www.researchgate.net/profile/Syed_Yusuf_Saadat/publication/329706897_Consumers'_Perception S_on_Car_Sharing_A_Preliminary_Study_in_Dhaka_City/links/5c17627a92851c39ebf3252a/ConsumersPerceptions-on-Car-Sharing-A-Preliminary-Study-in-Dhaka-City.pdf.

20.Shmueli, E. et al. (2015). Ride Sharing: A Network Perspective. Springer International Publishing, pp. 434-439. Doi: 10.1007/978-3-319-16268-3_55.

21.Stiglic, M., Agatz, N., Savelsbergh, M. \& Gradisar, M. (2016). Making dynamic ride-sharing work: The impact of driver and rider flexibility. Transport Research Part E, 91, 190-207. Doi: $10.1016 /$ j.tre.2016.04.010.

22.Teubner, Timm \& Flath, Christoph (2015). The Economics of Multi-Hop Ride Sharing, Business \& Information Systems Engineering. The International Journal of WIRTSCHAFTSINFORMATIK, Springer; Gesellschaft für Informatik e.V. (GI), 57(5), 311-324, October. DOI: 10.1007/s12599-015-0396-y.

23.Transport for London (2007). Car Share Guide, Mayor of London, London. 